\title{
SDF1 induction by acidosis from principal cells regulates intercalated cell subtype distribution
}

\author{
George J. Schwartz, ${ }^{1}$ XiaoBo Gao, ${ }^{2}$ Shuichi Tsuruoka, ${ }^{3}$ Jeffrey M. Purkerson, ${ }^{1}$ Hu Peng, ${ }^{1}$ Vivette D'Agati, ${ }^{4}$ Nicolas Picard, ${ }^{5}$ \\ Dominique Eladari, ${ }^{5}$ and Qais Al-Awqati ${ }^{2}$
}

'Department of Pediatrics, University of Rochester Medical Center, Rochester, New York, USA. ²Department of Medicine, Columbia University College of Physicians and Surgeons, New York, New York, USA. ${ }^{3}$ Department of Clinical Pharmacology, Jichi Medical School, Minamikawachi, Tochigi, Japan. ${ }^{4}$ Department of Pathology and Cell Biology, Columbia University College of Physicians and Surgeons, New York, New York, USA. ${ }^{5}$ INSERM UMR S970, Paris Cardiovascular Research Center (PARCC), Paris, France.

\begin{abstract}
The nephron cortical collecting duct (CCD) is composed of principal cells, which mediate $\mathrm{Na}$, $\mathrm{K}$, and water transport, and intercalated cells (ICs), which are specialized for acid-base transport. There are two canonical IC forms: acid-secreting $\alpha$-ICs and $\mathrm{HCO}_{3}$-secreting $\beta$-ICs. Chronic acidosis increases $\alpha$-ICs at the expense of $\beta$-ICs, thereby increasing net acid secretion by the CCD. We found by growth factor quantitative PCR array that acidosis increases expression of mRNA encoding SDF1 (or CXCL12) in kidney cortex and isolated CCDs from mouse and rabbit kidney cortex. Exogenous SDF1 or pH 6.8 media increased $\mathrm{H}^{+}$secretion and decreased $\mathrm{HCO}_{3}$ secretion in isolated perfused rabbit CCDs. Acid-dependent changes in $\mathrm{H}^{+}$and $\mathrm{HCO}_{3}$ secretion were largely blunted by AMD3100, which selectively blocks the SDF1 receptor CXCR4. In mice, diet-induced chronic acidosis increased $\alpha$-ICs and decreased $\beta$-ICs. Additionally, IC-specific Cxcr4 deletion prevented IC subtype alterations and magnified metabolic acidosis. SDF1 was transcriptionally regulated and a target of the hypoxia-sensing transcription factor HIF1 $\alpha$. IC-specific deletion of Hif1a produced no effect on mice fed an acid diet, as $\alpha$-ICs increased and $\beta$-ICs decreased similarly to that observed in WT littermates. However, Hif1a deletion in all CCD cells prevented acidosis-induced IC subtype distribution, resulting in more severe acidosis. Cultured principal cells exhibited an HIF1 $\alpha$-dependent increase of Sdf1 transcription in response to media acidification. Thus, our results indicate that principal cells respond to acid by producing SDF1, which then acts on adjacent ICs.
\end{abstract}

\section{Introduction}

The kidney responds to an acid load by increasing the rate of net $\mathrm{H}^{+}$secretion in the proximal and collecting tubules as well as by increasing the capacity to excrete net acid through stimulation of $\mathrm{NH}_{3}$ synthesis largely in the proximal tubule. $\mathrm{Net} \mathrm{H}^{+}$secretion in the collecting tubule is mediated by intercalated cells (ICs), which are present in two forms: (a) $\alpha$-ICs, which secrete $\mathrm{H}^{+}$by an apical $\mathrm{H}^{+}$-ATPase and a basolateral $\mathrm{Cl}: \mathrm{HCO}_{3}$ exchanger, AE1, and (b) $\beta$-ICs, which secrete $\mathrm{HCO}_{3}$ by an apical pendrin and a basolateral $\mathrm{H}^{+}$ATPase. Net acid secretion in this segment is thus the sum of these two processes. In the collecting tubule, as in the other acidifying segment (the proximal tubule), there are acute and chronic responses to an acid load. Acute responses might include the following: exocytosis of vesicles containing $\mathrm{H}^{+}$ATPases, thereby increasing the number of proton pumps on the surface $(1,2)$; assembly and disassembly of various subunits; and kinetic effects on the ATPase mediated by cytoplasmic acidification, kinetic activation of soluble adenyl cyclase (3), as well as by hormones such as angiotensin II (4) and aldosterone (5).

The chronic response in the collecting duct occurs by alteration in the numbers of the two subtypes of ICs (6), a change that

Authorship note: George J. Schwartz and XiaoBo Gao contributed equally to this work Conflict of interest: The authors have declared that no conflict of interest exists. Submitted: November 26, 2014; Accepted: September 11, 2015.

Reference information: J Clin Invest. 2015;125(12):4365-4374. doi:10.1172/JCI80225. is complex and requires new RNA and protein synthesis (7). While this response is well documented and occurs in vivo, the mechanism by which these cells sense a change in blood $\mathrm{pH}$, which causes cellular acidification, is obscure. It is clear that sensing the lowered blood $\mathrm{pH}$ and the response of the epithelial cell can be entirely local to the cortical collecting duct (CCD). This was demonstrated when isolated perfused rabbit cortical collecting tubules were incubated for 3 hours in acid media. A study of individually identified $\mathrm{HCO}_{3}$-secreting cells showed that they lost their apical $\mathrm{Cl}: \mathrm{HCO}_{3}$ exchange activity, and some began to express basolateral $\mathrm{Cl}: \mathrm{HCO}_{3}$ exchange (7). The discovery that polymerization of the extracellular protein hensin (DMBT1) (8) was critical to this process again confirmed the role of local factors produced by the collecting tubule (7). The question remains: how does the cell receive the acid signal, and what is its immediate response? Further, given that the collecting tubule contains two cell types - principal cells and ICs - we examined whether the IC itself is autonomous in the control of acid-base homeostasis at the level of the collecting duct, i.e., whether it receives as well as responds to the acid signal.

Here, we show that the proximate response of the cell is to induce the expression of SDF1 (also known as CXCL12), likely by activating the hypoxia transcription pathway, which, by itself, is sufficient to induce chronic adaptation, whereby the proportion of acid- and bicarbonate-secreting cells is changed. The most surprising finding, however, is that it is the principal cell that is the sensor 


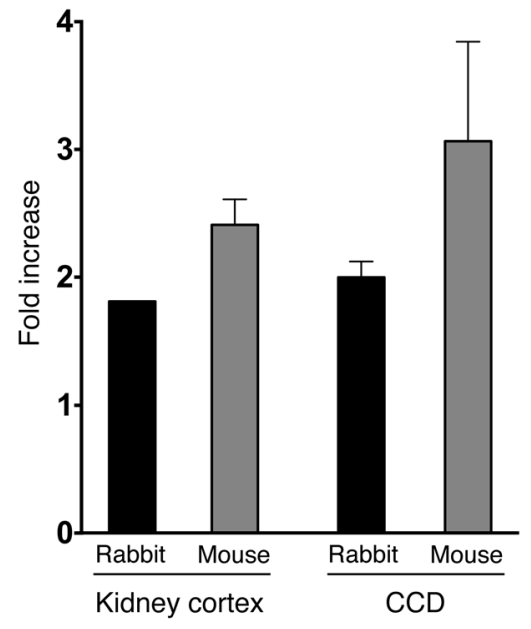

for the acid signal, a cell that heretofore had been thought to be dedicated to $\mathrm{Na}, \mathrm{K}$, and water transport but not to acid-base transport.

\section{Results}

Metabolic acidosis induces SDF1 in CCDs. We induced metabolic acidosis in mice by feeding them an acid diet $\left(0.1 \mathrm{~g} \mathrm{NH}_{4} \mathrm{Cl} / \mathrm{g}\right.$ food), isolated renal cortex mRNA, and used a growth factor PCR array (SABiosciences, QIAGEN) to assess expression of 89 growth factors. Comparison of mRNA from mice fed a normal diet with that from mice fed an acid diet for 2 days showed that acidosis increased expression of the following factors: Fgf2, Sdf1 (Cxcl12), Bdnf, Gdnf, Lefty2, and Inhba (Supplemental Table 1; supplemental material available online with this article; doi:10.1172/JCI80225DS1). However, confirmation by quantitative PCR (qPCR) showed that only $S d f 1$ was increased consistently by acidosis (qPCR of $S d f 1 /$ Gapdh mRNA showed an $\sim$-fold
Figure 1. qPCR of SDF1 (CXCL12) in kidney from normal and acidotic animals. qPCR was performed on kidney cortex mRNA from animals fed a normal diet and compared with kidney cortex mRNA from animals fed an acid diet for 2 days. Rabbit and mouse kidney cortex mRNA was normalized to Atp6v1b1 (rabbit, $n=4$ ) and Gapdh (mouse, $n=4$ ). CCDs from transgenic mice expressing GFP in the ICs were isolated using the COPAS sorter and were normalized to Gapdh.

increase in acidosis over that seen in mice fed a normal diet, $n=4$ ) (Figure 1). We isolated CCDs from mice expressing GFP in their ICs using a complex object parametric analyzer and sorter (COPAS) and found that feeding mice an acid diet for 3 days also resulted in a substantial induction of $S d f 1$ mRNA (Figure 1). We extended these studies to another species and found that a similar induction of SDF1 occurs in kidney cortex mRNA and in isolated CCDs from rabbits fed an acid diet for 3 days (Figure 1). We had previously found that SDF1 and its receptor CXCR4 are widely expressed in the kidney (9).

ISH showed that in mice fed an acid diet, there was increased expression of SDF1 in cortical and outer medullary collecting tubules (Figure 2). Remarkably, however, the S1 segment of the proximal tubule had the highest level of expression.

Although we made intensive efforts to provide evidence for an increase in protein expression using Western blotting, IHC, and ELISA, we were unable to detect a signal, despite the use of three independently produced Abs.

SDF1 increases $\mathrm{H}^{+}$secretion and decreases $\mathrm{HCO}_{3}$ secretion in rabbit CCDs. The CCD is capable of both $\mathrm{HCO}_{3}$ absorption (i.e., $\mathrm{H}^{+}$secretion) and $\mathrm{HCO}_{3}$ secretion, each of which is mediated by a different IC type. To evaluate the fluxes produced by each cell type, we performed $\mathrm{H}^{+}$and $\mathrm{HCO}_{3}$ transport studies in isolated perfused rabbit CCDs using methods described previously $(6,7)$.
Figure 2. ISH of SDF1 in mouse kidney cortex and medulla. (A) Images of the CCD and S1 segment of the proximal tubule. (B) Images of OMCDs. Note the thick ascending limb, which shows a high brown background but not much SDF1 staining. (C) Image of the S1 proximal tubule connecting with the glomerulus. Images were taken from mice fed a normal diet or a 2-day acid diet. Representative samples from 2 independent studies. Arrows in the CCD and OMCD images indicate heterogeneous, lower-intensity staining in different cells of these structures compared with more homogeneous staining in the $\mathrm{S} 1$ segment. Original magnification, $\times 600$. G, glomerulus; PT, proximal tubule; ThAL, thick ascending limb.
A

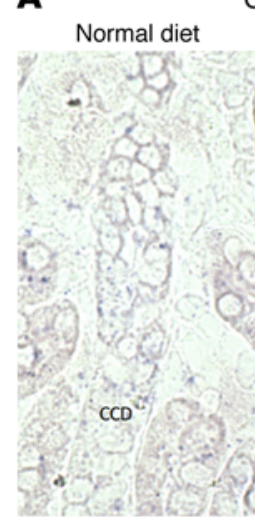

C CCD

Acid diet

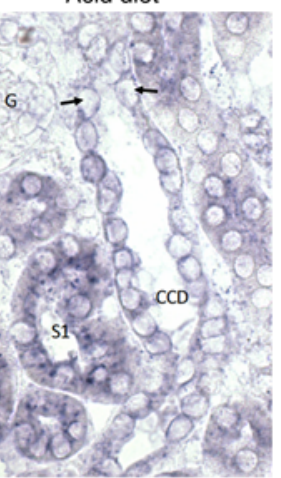

S1 PT

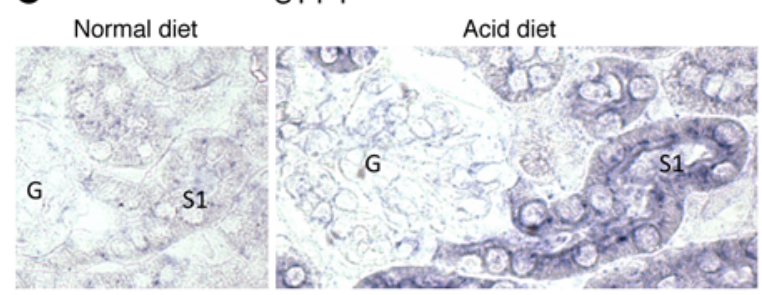

B

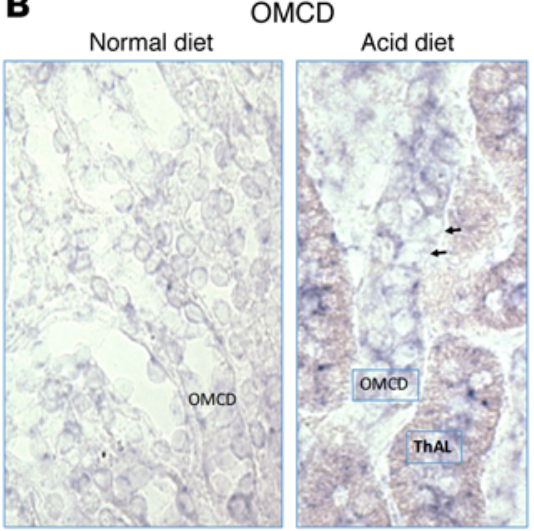




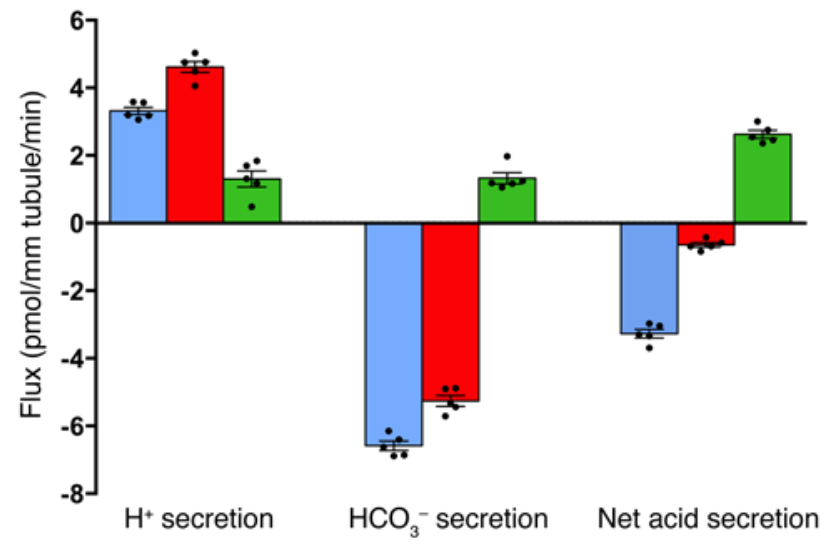

$\mathrm{HCO}_{3}$ is secreted into the lumen by the $\beta$-IC, which has a $\mathrm{Cl}: \mathrm{HCO}_{3}$ exchanger (pendrin) in the apical membrane and a $\mathrm{H}^{+}$ATPase in the basolateral membrane. $\mathrm{HCO}_{3}$ is absorbed by the $\alpha$-IC, which has an apical $\mathrm{H}^{+}$ATPase and a basolateral Cl: $\mathrm{HCO}_{3}$ exchanger. In the $\mathrm{CCD}$, net $\mathrm{HCO}_{3}$ transport is first measured as the change in $\mathrm{HCO}_{3}$ concentration in the perfusate per unit time per unit length of CCD. Then, the perfusing medium is changed to a Cl-free solution, which inhibits the function of the $\beta$-IC, given that pendrin is a strict $\mathrm{Cl}: \mathrm{HCO}_{3}$ exchanger. The flux of $\mathrm{HCO}_{3}$ remaining in the absence of luminal $\mathrm{Cl}$ is therefore that of $\mathrm{HCO}_{3}$ absorption (i.e., $\mathrm{H}^{+}$secretion) by the $\alpha$-IC. Figure 3 and Table 1 provide the results of these studies (fluxes are given in $\mathrm{pmol} / \mathrm{min} / \mathrm{mm}$ tubule length). These fluxes were measured again (Figure 3, red bars) in the same tubules after a 3-hour incubation at $\mathrm{pH} 7.4$ in the presence of $10 \mathrm{nM}$ SDF1. SDF1 significantly $(P<0.01)$ increased $\mathrm{HCO}_{3}$ absorption $\left(\mathrm{H}^{+}\right.$secretion) and reduced $\mathrm{HCO}_{3}$ secretion compared with the fluxes observed during a 3-hour control incubation in the absence of SDF1.

Blockade of the receptor for SDF1 inhibits the acid-mediated change in acid-base transport. CXCR4 is the receptor for SDF1, and we used its selective inhibitor AMD3100 (plerixafor) to examine the role of the SDF1/CXCR4 axis in the response of the tubule to acid incubation (Figure 4 and Table 2). After an initial control period during which fluxes were measured at $\mathrm{pH} 7.4$ (Figure 3, blue bars), tubules were exposed to an acid-bathing medium ( $\mathrm{pH} 6.8$ ) for 3 hours, and transport rates were measured again (red bars with [Figure 4B] or without [Figure 4A] $1 \mu \mathrm{M}$ AMD3100; rates are in
Figure 3. Effect of $10 \mathrm{nM}$ SDF1 on acid-base transport in isolated perfused rabbit CCDs. Net acid secretion was measured as the change in $\mathrm{HCO}_{3}$ concentration, after which the perfusate was changed to a $\mathrm{Cl}$-free medium and the net acid-base transport measured again. Removal of $\mathrm{Cl}$ blocked $\mathrm{HCO}_{3}$ secretion, thereby uncovering $\mathrm{H}^{+}$secretion. After a period of control collections (blue bars), SDF1 was added to the bathing medium for 3 hours and the fluxes measured again (red bars). Green bars show the difference between SDF1 and control fluxes. Numerical values are provided in Table 1. Data represent the mean $\pm \mathrm{SEM} ; n=5$.

$\mathrm{pmol} / \mathrm{min} / \mathrm{mm}$ tubule length). Note that acid media (Figure 4 , red bars) changed net $\mathrm{HCO}_{3}$ secretion to net $\mathrm{HCO}_{3}$ absorption (compare the -3.8 blue bar, which changed to a +2.6 red bar in Figure $4 \mathrm{~A})$. The change in net flux was produced by a reduction in $\mathrm{HCO}_{3}$ secretion and an increase in $\mathrm{H}^{+}$secretion, but when the acid media contained AMD3100 (Figure 4B), the normal response to acidosis was prevented (compare the net acid secretion of +0.4 [red bar] in Figure $4 \mathrm{~B}$ with that of +2.6 [red bar] in Figure $4 \mathrm{~A}$ ). Figure $4 \mathrm{C}$ shows that the 3-hour incubation at a constant $\mathrm{pH}$ of $7.4 \mathrm{did}$ not alter the rates of acid-base transport. These results demonstrate in the aggregate that SDF1 mediates the effect of extracellular acidosis to increase $\mathrm{H}^{+}$secretion and decrease $\mathrm{HCO}_{3}$ secretion largely through its action on its receptor CXCR4.

Does the SDF1/CXCR4 pathway mediate change in the proportion of $\beta$ - and $\alpha$-ICs? The response of the CCD to acidosis might involve acute stimulation of $\mathrm{H}^{+}$secretion and inhibition of $\mathrm{HCO}_{3}$ secretion through processes such as a change in the abundance of various transporters on the cell membrane. Alternatively, it might mediate a change in the number of $\alpha$-ICs and/or $\beta$-ICs, which occurs in states of chronic acidosis. To examine whether SDF1 affects the abundance of the different subtypes of ICs, we induced acidosis in mice and measured the number of $\alpha$ - and $\beta$-ICs in the cortex. We define $\alpha$-ICs as those cells with apical $\mathrm{H}^{+}$ATPase and a basolateral AE1 and $\beta$-ICs as those with apical pendrin and a basolateral $\mathrm{H}^{+}$ ATPase. In each study, the response of mutant mice and their nonmutant littermates to an acid diet was compared. The littermates are referred to herein as WT mice for simplicity.

Table 1. Effect of $10 \mathrm{nM}$ SDF1 added to the bathing medium on $\mathrm{H}^{+}$and $\mathrm{HCO}_{3}$ fluxes in isolated perfused rabbit CCDs

\begin{tabular}{|c|c|c|c|c|c|c|c|c|c|c|}
\hline & \multicolumn{3}{|c|}{ Before acid incubation } & & \multicolumn{3}{|c|}{ +3-hour incubation } & \multicolumn{3}{|c|}{ Difference } \\
\hline & $\mathrm{JH}^{+}$ & $\mathrm{JHCO}_{3}$ & Jnet & & $\mathrm{JH}^{+}$ & $\mathrm{JHCO}_{3}$ & Jnet & $\Delta \mathrm{JH}^{+}$ & $\triangle \mathrm{JHCO}_{3}$ & $\Delta$ Jnet \\
\hline Vehicle & & & & Vehicle & & & & & & \\
\hline Average & 3.23 & -6.57 & -3.34 & & 3.5 & -6.87 & -3.37 & 0.27 & -0.30 & -0.03 \\
\hline Vehicle & & & & +10 nM SDF1 & & & & & & \\
\hline Average & 3.32 & -6.58 & -3.27 & & $4.62^{\mathrm{A}}$ & $-5.26^{A}$ & $-0.64^{A}$ & $1.30^{\mathrm{A}}$ & $1.33^{\mathrm{A}}$ & $2.63^{\mathrm{A}}$ \\
\hline
\end{tabular}

After measurement of initial fluxes, the bathing medium was changed to contain SDF1 or its vehicle. After a 3-hour incubation, fluxes were measured again. All solutions were at $\mathrm{pH}$ 7.4. The reported studies are an average of 5 independent studies. ${ }^{A} P<0.01$ using a 2-tailed paired $t$ test. J, flux; Jnet, net flux. 

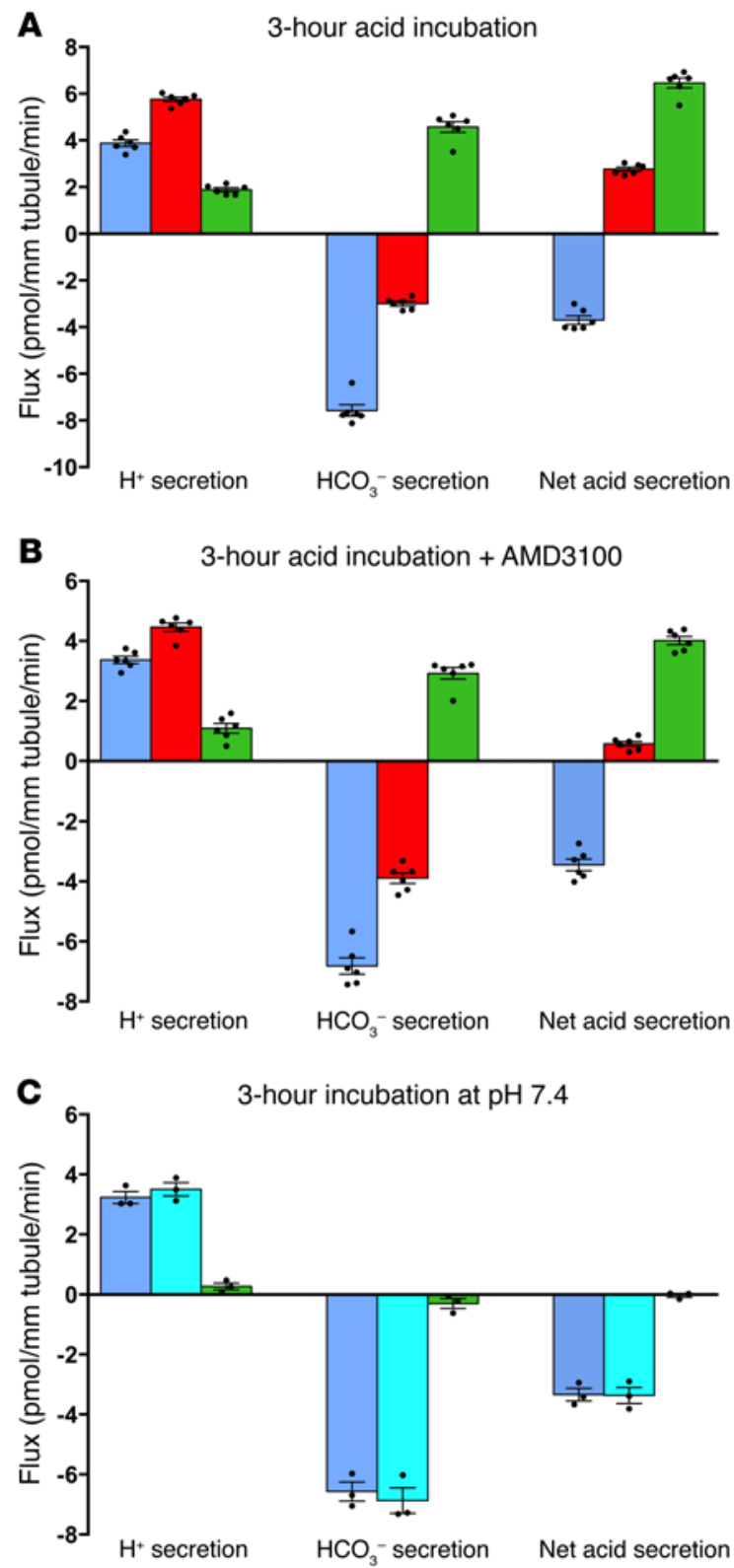

To investigate whether the SDF1/CXCR4 pathway is critical to the process of remodeling, we deleted $\mathrm{Cxcr} 4$ in all ICs by crossing Cxcr4-floxed mice ( $\mathrm{Cxcr} 4^{f / f l}$ ) (a gift of Dan Littman, New York University [NYU], New York, New York, USA) with those carrying Cre under control of the promoter of the VB1 subunit of vacuolar ATPase [Tg(ATP6V1B1-Cre ), herein referred to as VB1-Cre], a promoter whose renal activity is limited to the ICs (Supplemental Figure 1) (10). We stained kidney cortex sections for VB1 ATPase, AE1, or pendrin in mice with $\mathrm{Cxcr} 4$ deletion and in their WT littermates. Figure 5A (see also Supplemental Figure 3 and Supplemental Table 2) shows that in the cortex of WT mice fed a normal diet (blue bars), $56 \%$ of the ICs stained for AE1 (i.e., they were $\alpha$-ICs) and $44 \%$ were pendrin +ve ( $\beta$-ICs). When fed an acid diet for 2 days (Figure 5 , red bars), the fraction of $\mathrm{AE}^{+}$cells increased to $78 \%$, with a concomitant reduction of the pendrin ${ }^{+}$cells to $22 \%$. These results are similar to those of numerous other studies in different species in which acidosis increased $\alpha$-ICs and reduced $\beta$-ICs $(11,12)$. We found that in
Figure 4. Acid-base transport in isolated perfused rabbit CCDs: effect of the CXCR4 antagonist AMD3100. Tubules were perfused and fluxes were measured at $\mathrm{pH} 7.4$, following which the bathing medium was replaced with the same solution, except at $\mathrm{pH}$ 6.8. Three hours later, fluxes were measured again. (A) Initial fluxes at pH 7.4 (blue bars) and effect of a 3 -hour incubation at pH 6.8 (red bars); $n=6$. The difference between these 2 fluxes is indicated in the green bars. (B) Same as in $\mathbf{A}$, except the medium contained $1 \mu$ M AMD3100; $n=6$. (C) Initial fluxes at $\mathrm{pH} 7.4$ (blue bars) and the effect of a 3-hour incubation at pH 7.4 (aqua bars); $n=3$. Data represent the average \pm SEM. Numerical values of the mean \pm SEM are provided in Table 2 .

mice deleted for Cxcr4 in the IC lineage, 39\% were AE1 ${ }^{+}$(and 61\% were pendrin ${ }^{+}$). However, acid feeding had no effect on the proportion of $\mathrm{AE}^{+}$or pendrin ${ }^{+}$cells. These results represent studies of 4 mice in the Cxcr4-KO lineage and 12 WT mice. In each group of 4 mice, we counted 6,576-8,863 ICs (Supplemental Table 2). In other studies, in which we stained for aquaporin 2 and VB1 ATPase, the mutations (or acidosis) had no effect on the ratio of intercalated to principal cells (data not shown).

To confirm the role of this pathway in whole-body acid-base balance, we measured the plasma $\mathrm{HCO}_{3}$ concentration and found that when WT littermates were fed an acid diet for 3 days, their plasma $\mathrm{HCO}_{3}$ decreased by approximately $3.8 \mathrm{mEq} / \mathrm{l}$. However, the same acid diet in the mutant mice caused a decrease of almost twice the level of that in their littermates (Table 3). These studies demonstrate that SDF1 and its receptor CXCR4 are critical for determining the response of ICs to acidosis.

These results show that the SDF1/CXCR4 pathway mediates the effect of acidosis on IC remodeling in the CCD. However, SDF1 binds and activates another $\mathrm{G}$ protein-coupled receptor, CXCR7 (13). We found that this alternative receptor was expressed in the collecting tubule at levels similar to those of CXCR4 (Supplemental Figure 2). As shown above, deletion of Cxcr4 inhibited tubular adaptation by more than $80 \%$, suggesting that it is the major receptor for SDF1 in these segments during acidosis. Whether CXCR7 signaling contributes to the effects of acidosis on ICs will require more definitive studies.

Which cell in the renal tubule produces SDF1 in response to acidosis? Since isolated collecting tubules by themselves are capable of producing SDF1 (Figure 1), we asked which of its two cell types, principal or intercalated, was responsible for SDF1 production. SDF1 and CXCR4 are targets of the hypoxia-sensing transcription factor HIF1 $\alpha$ (14). Regulation of SDF1 production is thought to be largely (or entirely) due to the transcriptional activity of HIF proteins rather than to the release of stored material in the cell. To identify the acid-sensing cell, we first crossed Hifla-floxed mice $\left(H i f 1 a^{f l / f l}\right)$ with two Cre-expressing lines. In one line, we deleted Hifla from the intercalated lineage (using the VB1-Cre line; Figure 5B). Surprisingly, in response to an acid diet, the number of $\alpha$-ICs increased and the number of $\beta$-ICs decreased in a quantitative manner nearly identical to that of their WT littermates. Similarly, the acid-base balance in the whole animal, as reflected by reductions in the plasma $\mathrm{HCO}_{3}$ concentration, was similar to that of WT mice (Table 1). This result suggests that SDF1 continued to be active in the absence of its major regulator in the IC. Given that the effect of SDF1 was blocked by AMD3100 in isolated perfused tubules (Figure 4) and that it was produced by isolated CCDs 
Table 2. Effect of $1 \mu \mathrm{M}$ AMD3100 on $\mathrm{H}^{+}$and $\mathrm{HCO}_{3}$ fluxes in isolated perfused rabbit CCDs

\begin{tabular}{|c|c|c|c|c|c|c|c|c|c|c|}
\hline & \multicolumn{3}{|c|}{ Before acid incubation } & & \multicolumn{3}{|c|}{+3 -hour acid incubation } & \multicolumn{3}{|c|}{ Difference } \\
\hline & $\mathrm{JH}^{+}$ & $\mathrm{JHCO}_{3}$ & Jnet & & $\mathrm{JH}^{+}$ & $\mathrm{JHCO}_{3}$ & Jnet & $\Delta \mathrm{JH}^{+}$ & $\Delta \mathrm{JHCO}_{3}$ & $\Delta$ Jnet \\
\hline Vehicle & & & & Vehicle & & & & & & \\
\hline SD & 0.34 & 0.60 & 0.45 & & 0.24 & 0.25 & 0.22 & 0.21 & 0.56 & 0.51 \\
\hline Vehicle & & & & +100 $\mu$ M AMD3100 & & & & & & \\
\hline Average & 3.37 & -6.82 & -3.45 & & $4.46^{\mathrm{A}}$ & $-3.89^{A}$ & $0.57^{\mathrm{A}}$ & $1.09^{A}$ & $2.93^{\mathrm{A}}$ & $4.02^{A}$ \\
\hline
\end{tabular}

After measurement of initial fluxes, the bathing medium was changed to one with a pH of 6.8 as described in Methods. After a 3-hour incubation, fluxes were measured again. AMD3100 was added, and the reported studies are an average of 6 independent studies. ${ }^{A} P<0.01$ using a 2-tailed unpaired $t$ test. $n=6$ independent studies for each group.

(Figure 1), it is likely that it was produced by the principal cell. SDF1 is poorly diffusible and tightly binds to a variety of extracellular matrix proteins (15).

To test the hypothesis that the adjacent principal cells might be producing SDF1, we deleted Hifla from both principal cells and ICs (using the Hoxb7-Cre line; Figure 5C). When Hifla was deleted from principal cells (and ICs), the response to acidosis was abolished. While the response in WT littermates to a 2-day acid challenge was an increase in $\alpha$-IC and a decrease in $\beta$-IC numbers, these numbers remained constant in mice lacking HIF1 $\alpha$ in principal cells (and ICs), despite the acid challenge. We also observed a substantially defective response of the kidney to an acid challenge, with a decrease of $6 \mathrm{mEq} / \mathrm{l}$ in $\mathrm{HCO}_{3}$ concentration in the mutant mice compared with a $3 \mathrm{mEq} / 1$ decrease in their WT littermates (Table 3). These results confirm the physiological significance of changes in the proportion of $\alpha$ - and $\beta$-ICs in response to SDF1.

To confirm this conclusion, we performed immunolocalization of SDF1 in rabbit kidney cortex to demonstrate the generality of this finding. The results shown in Figure 6 demonstrate that in rabbit kidney cortex and medulla, SDF1 was expressed in the collecting tubule only in the principal cells. Similarly, in the medulla of the kidney, a region known to be hypoxic and hence to have higher levels of HIF1 $\alpha$ expression, higher expression levels of this transcription factor were found only in the principal cells. Western blot analysis of mouse kidneys had previously shown that SDF1 expression levels are higher in the medulla than in the cortex (9). ISH (Figure 2) showed that SDF1 was induced by acidosis in the S1 segment as well as in the CCDs and outer medullary collecting ducts (OMCDs). Examination of the OMCD images showed that, while the majority of the cells expressed SDF1, there were always a few cells that lacked any expression (Figure 2B, arrows). Similar results were obtained in the CCDs (Figure 2A, arrows); however, there were far fewer images of CCDs that we were able to rigorously identify as CCDs, since no counterstain was used. Given that the majority of cells in the collecting tubule are principal cells, we suggest that this staining pattern confirms the conclusions of the Hifla-deletion studies. In summary, it appears that the ICs themselves do not produce SDF1 to provide paracrine signaling. Rather, when Hifla (and thus, presumably, SDF1) was deleted from principal cells as well, the results were very different, demonstrating, surprisingly, that the acid-sensing cell in the CCD is actually the principal cell, a cell heretofore not known to participate directly in acid-base balance.

While it is well known that SDF1 and CXCR4 are target genes of the HIF system, we investigated whether the activation of $S d f 1$ transcription was mediated entirely by HIF1 $\alpha$ and not some other acid-sensitive pathway such as the secretion of preformed SDF1. We used two CCD cell lines, M-1 (16) and mouse CCD (mCCD) (17) cells, which have many of the characteristics of principal cells of the collecting tubule. Using qPCR, we found that incubation of these cells at $\mathrm{pH} 6.8$ for 18 hours increased SDF1 transcription by $1.8 \pm 0.1$-fold in M-1 cells $(n=3)$ and by 1.8 -fold in MCCD cells $(n=2)$, levels similar to those detected in mRNA of both kidney cortex and isolated CCDs (Figure 1). When these cells were exposed to acid media in the presence of $5 \mu \mathrm{M}$ acriflavine, a drug that interrupts the dimerization of HIF1 $\alpha$ and ARNT (18), qPCR showed that $S d f 1$ transcription levels were drastically reduced to 0.24-fold of the levels detected in the control cell line incubated at $\mathrm{pH}$ 7.4. At this dose, acriflavine had no deleterious effect on cell survival in our studies or in studies in other cells (18). Acid incubation of M-1 cells also caused a 1.8-fold increase in transcription of carbonic anhydrase IX, a classic target gene of HIF1. Further, HIF1 transcription factors are hydroxylated on prolines by prolyl hydroxylases that utilize $\alpha$-ketoglutarate and oxygen as substrates. Prolyl hydroxylation allows vHL to bind and ubiquitinate HIF proteins, thereby causing their degradation. Addition of a permeable $\alpha$-ketoglutarate to acid-incubated M- 1 and mCCD cells reduced the expression levels of $S d f 1$ to 0.5 -fold from 1.8 -fold. These results demonstrate that the acid-sensing pathway causes an increase in SDF1 production through activation of HIF1 $\alpha$.

\section{Discussion}

The renal response to chronic acidosis is mediated by ammoniagenesis, which occurs in the proximal tubule (19), and by an increase in proton secretion in the collecting tubule. Acidosis causes an increase in the number of acid-secreting cells at the expense of $\mathrm{HCO}_{3}$-secreting cells (6). Proliferation of acid-secreting $\alpha$-ICs was also reported in some studies $(20,21)$. In the outer medullary collecting tubule, there is also an increase in the amount of acid secreted by each cell in chronic acidosis (22). While, in principle, many mechanisms might be invoked to mediate this critical homeostatic response, it is clear that the machinery for regulation 

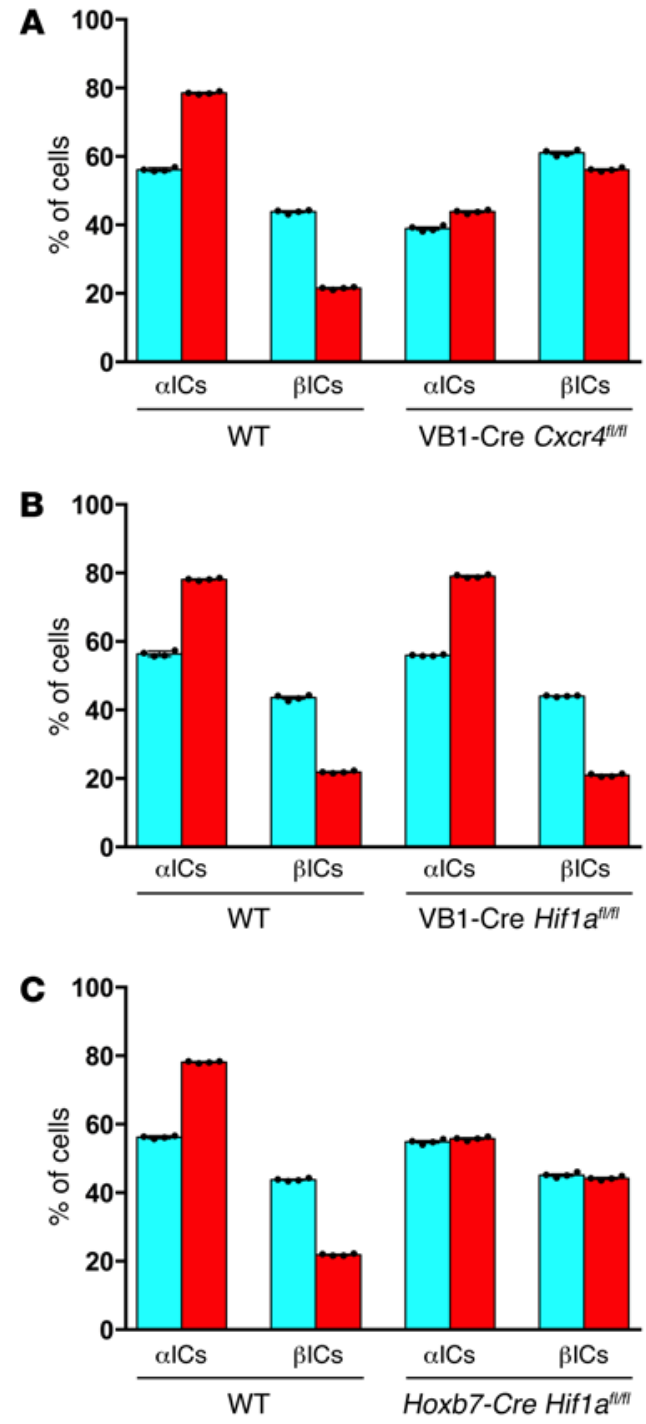

Figure 5. Distribution of IC subtypes in kidney cortex from control and KO mice. ICs were identified as those cells expressing the B1 subunit of the $\mathrm{H}^{+}$ATPase, $\alpha-I C s$ as those that also expressed KAE1, and $\beta$-ICs as those that expressed pendrin. (A-C) Each panel represents studies performed in 4 mice fed a normal diet (blue bars) and 4 littermates fed a pellet diet containing $2 \% \mathrm{NH}_{4} \mathrm{Cl}$ (red bars). Each bar represents the average ( $\pm S D$ ) of the cell counts from 4 mice. For each study in $\mathbf{A}-\mathbf{C}$, we examined 8 mice expressing the active Cre recombinase and another 8 mice that were their WT littermates. Four mice of each genotype were fed a normal diet and the other 4 an acid-supplemented diet. In each group of 4 mice, we counted between 6,576 and 8,863 ICs (the raw data are provided in Supplemental Table 2).

of the chronic response is present in the CCD without any need to invoke freely circulating factors. Here, we show that activation of the hypoxia-signaling pathway occurs during acidosis and that one consequence of this activation is the production of the chemokine SDF1 (CXCL12). The most surprising finding is that it appears to be the principal cell, not the IC, that responds to acidosis by activating the HIF pathway.

SDF1 is a basic growth factor with limited diffusion capacity. It is well known to bind to extracellular matrix components, especially glycosaminoglycans, heparin sulfates, and other com- ponents located at the cell surface and in the extracellular matrix (23). We previously found that all cells in the collecting tubule produce the extracellular matrix protein hensin (DMBT1), yet during acidosis, it is polymerized and deposited underneath the acidsecreting cell (24). SDF1 is perhaps bound to hensin and thus might be presented to its receptor on the basolateral surface of the IC. SDF1, when produced by a principal cell, needs to diffuse across only the intercellular space to the adjacent IC to exert its effect. Since principal cells outnumber ICs by a factor of approximately 2 , each IC abuts at least 1 principal cell. Thus, acidosis has the capability of activating every IC.

Unfortunately, despite a large effort by the three laboratories involved in our collaborative work, we have failed to detect induction of SDF1A protein by acidosis while using three independently produced (commercial and private) Abs. Even though we were able to demonstrate such activities previously at one of our laboratories (9), it has been frustratingly difficult to reproduce these findings. Perhaps the reason for our previous success was that the kidneys became hypoxic or ischemic, either of which is a potent stimulus for HIF1 activation.

How might the principal cell respond to acidosis? In general, all cells contain acid-transporting proteins (e.g., $\mathrm{Na}: \mathrm{H}$ or $\mathrm{Cl}: \mathrm{HCO}_{3}$ exchangers), and medium acidification will change the driving forces for proton $/ \mathrm{HCO}_{3}$ transport, leading to cellular acidification. Indeed, acidification of the media bathing the collecting tubules was found to acidify the cytoplasm of principal cells (25, 26). However, alternative (or additional) signaling mechanisms have been proposed, whereby proton-sensing $G$ protein-coupled receptors might mediate the effect of acidosis; indeed, deletion of Gpr4 led to renal tubular acidosis (RTA) (27).

How cell acidification might activate the hypoxia-signaling mechanism remains to be determined. Cellular acidosis might either reduce expression of vHL (or remove it from the cytoplasm), or inhibit the activity of prolyl hydroxylase(s). Acidosis was found to activate HIF1 $\alpha$ in some cells in culture, as demonstrated in a recent study showing that exposure of cells in culture to acidosis resulted in activation of HIF1 $\alpha$ due to the sequestration of $\mathrm{vHL}$ in the nucleolus (28). However, testing of this hypothesis in several cell lines revealed that this effect occurred in some lines, but did not appear to be a universal response (29). Prolyl hydroxylases require $\alpha$-ketoglutarate as a substrate and produce succinate as a product. It is possible that acidosis alters cellular metabolism in such a way as to reduce the concentration of the substrate or increase that of the product. It will be necessary to perform studies in principal cells of the collecting tubule, where the role of these two possible mechanisms can be directly examined.

One of the important recent clinical discoveries has been the identification of acidosis as a mediator of worsening kidney function. Treatment of patients with chronic kidney disease (CKD) with oral sodium bicarbonate reduced the rate of progression of renal failure (30). Similarly, large-scale epidemiologic and clinical studies showed that the lower the serum $\mathrm{HCO}_{3}$, the worse the outcome for kidney function (31). How could acidosis produce this progression? Acidosis induces the production of endothelin, a factor that might lead to progression (32). It is interesting to note that endothelin is also a target gene of HIF1 $\alpha$ (33). There is also extensive evidence that endothelin- 1 itself can activate HIF1 $\alpha$ (reviewed in ref. 34), sug- 
Table 3. $\mathrm{HCO}_{3}$ concentration (in mEq/I) in WT and mutant mice fed a normal diet or an acid-supplemented diet for 3 days

\begin{tabular}{|c|c|c|c|c|c|c|c|c|}
\hline & Normal & Acid & $\Delta$ & & Normal & Acid & $\Delta$ & $\boldsymbol{\delta} \boldsymbol{\Delta}$ \\
\hline WT & $26.2 \pm 0.3$ & $22.4 \pm 0.2$ & $3.79 \pm 0.7$ & VB1-Cre $C x c r 4^{f / / f l}$ & $26.7 \pm 0.9$ & $20.1 \pm 0.3$ & $6.6 \pm 1.3$ & $2.8 \pm 0.8^{A}$ \\
\hline WT & $26.3 \pm 0.5$ & $23.9 \pm 0.6$ & $2.35 \pm 0.13$ & VB1-Cre Hif1a fl/fl & $26.2 \pm 0.8$ & $24.4 \pm 0.1$ & $1.8 \pm 0.7$ & $0.7 \pm 0.6$ \\
\hline WT & $23.9 \pm 0.3$ & $21 \pm 0.7$ & $3.1 \pm 0.6$ & Hoxb7-Cre Hif1a fl/fI & $24.2 \pm 0.7$ & $18.6 \pm 0.7$ & $6.03 \pm 0.5$ & $3.0 \pm 0.9^{A}$ \\
\hline
\end{tabular}

Data represent \pm SD. Each group consisted of 4 mice. WT mice were littermates of the mutants and hence were not, strictly speaking, WT. ${ }^{A} P<0.01$.

gesting the possibility of a positive feedback system involving interaction of microvasculature and epithelial cells of the kidney.

SDF1 was discovered as a chemoattractant for a variety of inflammatory cells, and its s.c. injection led to skin invasion by lymphocytes (35). How might SDF1 injure the kidney? SDF1 attracts monocytes and lymphocytes, but not neutrophils, in vitro and in vivo (35). Since this discovery, a host of studies have continued to show the critical importance of SDF1 to the migration of BM-derived cells, including stem cells. Its receptor CXCR4 has been found to be highly expressed in all these cells as well as in macrophages and DCs. There is strong evidence for the involvement of SDF1/CXCR4 signaling in tissue inflammation in the kidney and other organs. In ischemic kidney injury, SDF1 is induced by epithelial cells of the nephron, leading to invasion by BM-derived cells (36). Wang et al. showed that all mouse models of lupus were associated with increased expression of SDF1 in the kidneys and invasion of CXCR4-expressing monocytes, B cell subsets, and plasma cells (37). Feeding animals a highprotein diet (which induces acidosis) was associated with invasion of the kidney by lymphocytes (38). Interestingly, studies of human renal biopsies from patients with CKD of various causes revealed local production of SDF1 in the collecting tubule and attraction of inflammatory cells to these discrete regions of the kidney (39). To our knowledge, no one has searched for invasion of immune cells into the kidney in states of "pure acidosis" such as RTA, probably because such patients rarely undergo biopsies and because tubulointerstitial disease is commonly a consequence and a cause of RTA. Further, in distal RTA, we often see nephrocalcinosis, which is likely due to $\mathrm{Ca}$ being leached out of bone, but which could also be due to acidosis-induced inflammation. Yet there are suggestions that the kidneys in acidotic patients are invaded by immune cells; half of the patients with methylmalonic aciduria (as pure an acidosis as one can get) develop significant renal failure (40) and most had tubulointerstitial infiltrates. Mice with dysfunctional $\mathrm{NaHCO}_{3}$ cotransporters develop severe acidosis, and their kidneys show substantial amounts of mononuclear cell infiltrates (41). On the basis of these studies, we propose that SDF1 plays a pathogenic role in the progression of CKD by attracting immune cells to the kidney and priming them there.

\section{Methods}

\section{Animals}

VB1-Cre mice were generated by Miller et al. (10), and the Hoxb7-Cre line was generated by Bates et al. (42). All mouse lines used in this study were on a C57BL6/6N background. The Cxcr4-floxed line was a gift of Dan Littman (NYU, New York, New York, USA) and have now been donated to and are available from The Jackson Laboratory (cat- alog 008767 B6.129P2 Cxcr4<tm2Yzo>/J). The Hifla-floxed line was purchased from The Jackson Laboratory (catalog 007561 B6.129Hifla $<$ tm3Rsjo $>/ \mathrm{J}$ ). Breeding of the mice was performed under the supervision of the Columbia University Animal Care Facility. Mice were placed in metabolic cages and given water and food ad libitum. Blood was collected using intracardiac or retro-orbital puncture and injected into a blood gas apparatus for determination of $\mathrm{pH}, \mathrm{PCO}_{2}$, and $\mathrm{HCO}_{3}$. All measurements were made in littermates of WT and mutant mice. When we tried to give the mice $\mathrm{NH}_{4} \mathrm{Cl}(280 \mathrm{mM})$ in the drinking water (in a $2 \%$ sucrose solution), they did not drink it and became dehydrated. We estimated the amount of $\mathrm{NH}_{4} \mathrm{Cl}$ needed to make the mice acidotic and their average food intake and asked a food supplier (TestDiet) to make $2 \% \mathrm{NH}_{4} \mathrm{Cl}$ mouse food in pellet form. The mice tolerated this much better but were still given $2 \%$ sucrose in water to induce a high urine volume. Blood gases were measured using a clinical blood gas analyzer. Mice were placed in metabolic cages for 2 days before the diet was changed. The urine $\mathrm{pH}$ declined after 1 day of the acid diet, and urine for net acid excretion was collected daily after the beginning of the acid diet. Rabbits were given $75 \mathrm{mM} \mathrm{NH}_{4} \mathrm{Cl}$ in the drinking water and restricted to $30 \mathrm{~g}$ per day of food to induce metabolic acidosis (7).

\section{CCD sorting}

Kidneys from VB1-GFP mice were prepared and collecting ducts sorted as previously described by Miller et al. (43). Acidosis in VB1-GFP mice was induced by adding $280 \mathrm{mM} \mathrm{NH}_{4} \mathrm{Cl}$ to the drinking water.

\section{Tissue fixation and preparation}

Animals were anesthetized with i.p. ketamine (75-95 mg/kg BW) and perfused through the left ventricle first with $\mathrm{PBS}(0.09 \% \mathrm{NaCl}$ in 10 $\mathrm{mM}$ phosphate buffer, $\mathrm{pH}$ 7.4), followed by pyridoxal-PLP fixative (4\% paraformaldehyde [PFA], $75 \mathrm{mM}$ lysine- $\mathrm{HCl}, 10 \mathrm{mM}$ sodium periodate, and $0.15 \mathrm{M}$ sucrose in $37.5 \mathrm{mM}$ sodium phosphate). Both kidneys were removed and sliced and were further fixed by immersion in PLP

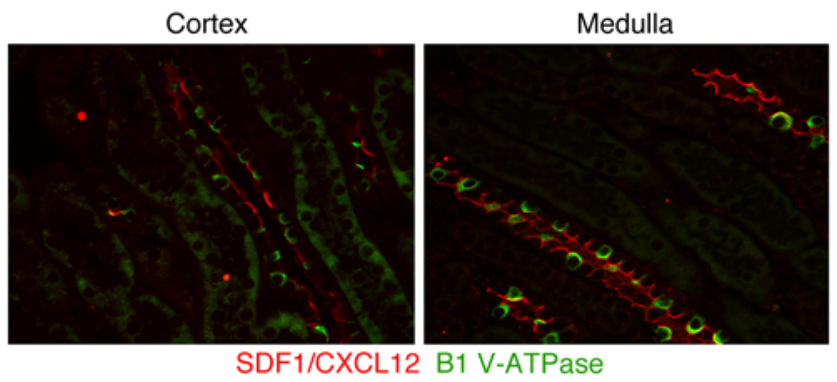

Figure 6. IHC of SDF1 in collecting ducts of rabbit kidney cortex and medulla. Red staining shows SDF1, and green staining shows the VB1 subunit of $\mathrm{H}^{+}$ATPase (i.e., ICs). Original magnification, $\times 400$. 
for 4 hours at room temperature and overnight at $4^{\circ} \mathrm{C}$, then extensively rinsed in $\mathrm{PBS}$ and stored at $4^{\circ} \mathrm{C}$ in $\mathrm{PBS}$ containing $0.02 \%$ sodium azide until use. To prepare frozen sections, tissues were cryoprotected by immersion in $0.9 \mathrm{M}(30 \%)$ sucrose in PBS overnight at $4^{\circ} \mathrm{C}$ and mounted for cryosectioning in Tissue-Tek (Sakura) before freezing in liquid nitrogen and sectioning at 5- $\mu \mathrm{m}$ thickness with a Leica CM3050 cryostat (Belair Instrument Company). Sections were picked up on Fisherbrand Superfrost Plus charged glass slides (Fisher Scientific).

\section{Immunofluorescence and confocal microscopy}

Fixed sections were hydrated in PBS for 10 minutes and treated by immersion in sodium citrate buffer $(10 \mathrm{mM}$ sodium citrate, $0.05 \%$ Tween-20, $\mathrm{pH}$ 6.0) at $95^{\circ} \mathrm{C}$ for 10 minutes for retrieval of antigenic sites. Sections were washed in PBS 3 times for 5 minutes and blocked in a solution of $1 \% \mathrm{BSA} / \mathrm{PBS} /$ sodium azide for 15 minutes to prevent nonspecific staining, followed by a 90 -minute incubation in the primary $\mathrm{Ab}$ at room temperature. After three 5-minute PBS washes, the secondary Ab was applied for 1 hour at room temperature, and the slides were then rinsed again in PBS 3 times for 5 minutes. Slides were mounted in fluorescent mounting medium (Dako, Agilent Technologies). For dual staining with Abs raised in different species, the primary Abs were applied sequentially at the appropriate concentrations, as described below, with each primary $\mathrm{Ab}$ being followed by the corresponding secondary Ab. Digital images were acquired with a Microphot SA EPIFL3 fluorescence microscope (Nikon Instruments) with a SPOT-RT 941 SE digital camera (SPOT Imaging Solutions, Diagnostic Instruments Inc.). Images were then analyzed using SPOT Advanced imageprocessing software and imported into and printed from Adobe Photoshop version 6.0 image-editing software (Adobe Systems). For confocal laser-scanning microscopy, tissue sections were prepared as described above. Confocal imaging was performed on an LSM 510 Meta confocal microscopy system (Carl Zeiss MicroImaging) using LSM Image Browser software, and images were edited as described above.

\section{Abs}

The following primary Abs were used: (a) an affinity-purified rabbit polyclonal $\mathrm{Ab}$ raised against rat $\mathrm{AE} 1$ anion exchanger at a dilution of 1:100 (Alpha Diagnostic; catalog AE11-A); (b) an affinity-purified rabbit polyclonal $\mathrm{Ab}$ raised against pendrin (Santa Cruz Biotechnology Inc.; catalog sc-50346); (c) a rabbit polyclonal Ab raised against AQP2 at a 1:100 dilution (Sigma-Aldrich; catalog A7310); (d) a rabbit polyclonal affinity-purified $\mathrm{Ab}$ raised against V-ATPase B1/2 at a dilution of 1:100 (Santa Cruz Biotechnology Inc.; catalog sc-20943); and (e) a mouse $\mathrm{mAb}$ raised against V-ATPase B1/2 at a dilution of 1:100 (Santa Cruz Biotechnology Inc.; catalog sc55544).

$A b$ s against SDF1. For SDF1 immunofluorescence, we used antiSDF1 goat polyclonal Ab (Santa Cruz Biotechnology Inc.; C-19, catalog sc-6193). We also used K15C mAb generated against the N-terminal peptide KPVSLSYRSPSRFFC. For SDF1 ELISA, we used a kit (Abcam; ab 100741, specific to mouse SDF1A) containing Abs against aa 22-89, which encompass all of SDF1A. Secondary Abs labeled with Texas Red (TR), TRITC (rhodamine), and FITC (fluorescein) were from Jackson ImmunoResearch and used at a dilution of 1:100 to 1:200 after reconstitution.

\section{Microperfusion of isolated CCDs from rabbits}

CCDs were microdissected from rabbit kidneys and perfused as described previously $(7,44)$. Three-hour incubations were performed at pH 7.4 and pH 6.8 (7). Net bicarbonate transport was measured using a WPI NanoFlo microfluorometer (World Precision Instruments). Cl-free solutions were perfused to separate $\mathrm{H}^{+}$and $\mathrm{HCO}_{3}$ fluxes as recently described (7).

\section{Microdissected mouse nephron segments}

Microdissected mouse nephron segments were isolated for qPCR of CXCR4 and CXCR7 as previously described (45). qPCR was performed with a SYBR Green amplification kit (Roche).

\section{Primers for qPCR and genotyping}

RNA was isolated and followed by clean-up with the PureLink RNA Mini Kit (Invitrogen) according to the manufacturer's instructions. For qPCR analysis, RNA was reverse transcribed and subjected to PCR amplification using either SYBR Green PCR Master Mix or TaqMan Universal PCR Master Mix on an AB 7500 platform (all from Applied Biosystems). mRNA expression levels were quantified using the relative standard curve method according to the manufacturer's instructions (Applied Biosystems).

The following mouse primer pairs were used for amplification: Sdf1: forward, 5'-CCGCTGCCGCACTTTCACTCT-3', reverse, 5'-GCTTGACGTTGGCTCTGGCGA-3'; carbonic anhydrase IX: forward, 5'-GCCACGCAACCCTTGAATG-3', reverse, 5'-AGTTTCTGTCATCTCTGCCGG-3'; Cxcr4: forward, AGCATGACGGACAAGTACC, reverse, GATGATATGGACAGCCTTACAC; Rpl26: forward, GCTAATGGCACAACCGTC, reverse, TCTCGATCGTTTCTTCCTTGTAT. Cxcr7 qPCR was performed using a TaqMan assay kit (Mm00432610_ $\mathrm{m} 1$ ) from Life Technologies. The following rabbit primer pairs were used for amplification of Sdf1: forward, 5'-AAACCCGTCAGCCTGAGCTACAGA-3', reverse, 5'-TCTTGAGATGCTTGACGTTGGCTC-3'. For VB1: forward, 5'-ATCAACGTGCTCCСTTCTCTGTCA, reverse, 5'-TGTGCAGGAATTCCAGGTAGAGCA.

The following mouse primer pairs were used for genotyping: VB1-Cre: forward, 5'-CATTACCGGTCGATGCAACGAG-3', reverse, 5'-TGCCCCTGTTTCACTATCCAGG-3'; Cxcr4 LoxP: forward: 5'-CCACCCAGGACAGTGTGACTCTAA-3', reverse, 5'-GATGGGATTTCTGTATGAGGATTAGC-3'; Hifla LoxP: forward, 5'-TGCTCATCAGTTGCCACTT-3', reverse, 5'-GTTGGGGCAGTACTGGAAAG-3'; HoxB7-Cre: forward, 5'-GGTCACGTGGTCAGAAGAGG-3', reverse, 5'-CTCATCACTCGTTGCATCGA-3'.

\section{ISH of SDF1 in mouse kidneys}

Probesynthesis for ISH. Mouse kidney mRNA was reverse transcribed into cDNA using SuperScript III First-Strand Synthesis SuperMix for qPCR (Invitrogen; catalog 11752-050), and a 222-bp fragment of the Sdf1 gene was amplified using the following primers: forward, 5'-CCGCTGCCGCACTTTCACTCT-3' and T7-embedded reverse, 5'-GGATTACCTAATACGACTCACTATAGgGATATGCTATGGCGgAGTGTCTT-3'. The PCR product was used as a template for in vitro transcription. Probe was synthesized by T7 RNA polymerase (Roche), and digoxigenin-labeled (DIG-labeled) RNA was subsequently purified by a PureLink RNA Mini Kit (Ambion, Life Technologies; catalog 12183018A).

ISH of frozen sections. Kidneys from mice fed a normal or acid diet (see above) were perfusion fixed, collected in ice-cold PBS, and fixed overnight at $4^{\circ} \mathrm{C}$ in $4 \%$ PFA in PBS and soaked in 30\% sucrose in PBS for 24 hours, then processed directly for embedding in OCT. Frozen sections $(8-\mu \mathrm{m})$ were air dried for 1 to 3 hours, then fixed in $4 \%$ 
PFA for 10 minutes at room temperature. After washing 3 times with PBS, sections were treated with proteinase $\mathrm{K}(1 \mu \mathrm{g} / \mathrm{ml}$ for 5 minutes at room temperature), then washed 3 times with PBS, acetylated for 10 minutes at room temperature, and washed again with PBS. Prehybridization was performed for 2 hours or overnight at room temperature in a humidified chamber. Hybridizations were performed at $68^{\circ} \mathrm{C}$ to $72^{\circ} \mathrm{C}$ overnight in a humidified chamber. Prehybridization and hybridization solution was composed of $50 \%$ formamide, $5 \times$ SSC, $5 \times$ Denhardt's solution, $250 \mu \mathrm{g} / \mathrm{ml}$ baker's yeast RNA (Sigma-Aldrich), and $500 \mu \mathrm{g} / \mathrm{ml}$ herring sperm DNA (Sigma-Aldrich). Washes were performed at $72^{\circ} \mathrm{C}$ in $5 \times \operatorname{SSC}$ for 5 to 10 minutes, then at $72^{\circ} \mathrm{C}$ in $0.2 \times$ SSC for 1 hour. Sections were stained overnight with anti-digoxigenin $\mathrm{Ab}$ (Boehringer Mannheim) at a 1:5,000 dilution in $0.1 \mathrm{M}$ Tris- $\mathrm{HCl}$, $\mathrm{pH} 7.5$, containing $0.15 \mathrm{M} \mathrm{NaCl}$ with $1 \%$ heat-inactivated goat serum. After staining overnight at $4^{\circ} \mathrm{C}$ in a humidified chamber, slides were washed in $0.1 \mathrm{M}$ Tris- $\mathrm{HCl}$ ( $\mathrm{pH} 7.5$ ) containing $0.15 \mathrm{M} \mathrm{NaCl}$. Alkaline phosphatase activity was detected by developing slides in BCIP/NBT (Boehringer Mannheim) and $0.25 \mathrm{mg} / \mathrm{ml}$ levamisole in a humidified chamber for 6 to 24 hours in the dark. Sections were dehydrated and mounted in Permount (Fisher Scientific).

\section{Statistics}

The data in the flux studies shown in Figures 3 and 4 were all analyzed in paired samples, hence the paired $t$ test was calculated using a 2-tailed test. For qPCR (Figure 1) and cell count results (Figure 5), SDs were calculated.

\section{Study approval}

All studies were conducted in accordance with protocols approved by the IACUCs of the Institutional Animal Care Facility of Columbia University and the University of Rochester School of Medicine. The studies performed in Paris were approved by the Comité d'éthique pour l'éxperimentation animale of the Université René Descartes (Paris, France).

\section{Author contributions}

QA, GJS, and DE designed the studies; GJS, XBG, ST, JMP, HP, NP, and VD'A performed various parts of the study; GXB, GJS, DE, and QA analyzed the data; QA wrote the manuscript; QA, GJS, and DE edited the manuscript.

\section{Acknowledgments}

This work was supported by NIH grants DK-20999 (to Q. AlAwqati) and DK-050603 (to G.J. Schwartz), and by grant ANR 14-CE12-0013-01/HYPERSCREEN Appel à projets générique 2014 from the Agence Nationale de la Recherche (to D. Eladari) and grant CHLORBLOCK from the IDEX Sorbonne Paris Cité (to D. Eladari).

Address correspondence to: Qais Al-Awqati, Department of Medicine, Columbia University, 622 West $168^{\text {th }}$ St, Room PH8E-111A, New York, New York 10032, USA. Phone: 212.305.3512; E-mail: qa1@cumc.columbia.edu.
1. Gluck S, Cannon C, Al-Awqati Q. Exocytosis regulates urinary acidification in turtle bladder by rapid insertion of $\mathrm{H}+$ pumps into the luminal membrane. Proc Natl Acad Sci U S A. 1982;79(14):4327-4331.

2. Schwartz GJ, Al-Awqati Q. Carbon dioxide causes exocytosis of vesicles containing $\mathrm{H}^{+}$pumps in isolated perfused proximal and collecting tubules. JClin Invest. 1985;75(5):1638-1644.

3. Păunescu TG, et al. cAMP stimulates apical V-ATPase accumulation, microvillar elongation, and proton extrusion in kidney collecting duct A-intercalated cells. Am J Physiol Renal Physiol. 2010;298(3):F643-F654.

4. Rothenberger F, Velic A, Stehberger PA, Kovacikova J, Wagner CA. Angiotensin II stimulates vacuolar $\mathrm{H}^{+}$-ATPase activity in renal acid-secretory intercalatedcells from the outer medullary collecting duct. JAm Soc Nephrol. 2007;18(7):2085-2093.

5. Al-Awqati Q, Norby LH, Mueller A, Steinmetz PR. Characteristics of stimulation of $\mathrm{H}^{+}$transport by aldosterone in turtle urinary bladder. J Clin Invest. 1976;58(2):351-358.

6. Schwartz GJ, Barasch J, Al-Awqati Q. Plasticity of functional epithelial polarity. Nature. 1985;318(6044):368-371.

7. Schwartz GJ, Tsuruoka S, Vijayakumar S, Petrovic S, Mian A, Al-Awqati Q. Acid incubation reverses the polarity of intercalated cell transporters, an effect mediated by hensin. J Clin Invest. 2002;109(1):89-99.

8. Al-Awqati Q, Gao XB. Differentiation of intercalated cells in the kidney. Physiology (Bethesda). 2011;26(4):266-272.
9. Oliver JA, et al. SDF-1 activates papillary label-retaining cells during kidney repair from injury. Am J Physiol Renal Physiol. 2012;302(11):F1362-F1373.

10. Miller RL, et al. The V-ATPase B1-subunit promoter drives expression of Cre recombinase in intercalated cells of the kidney. Kidney Int. 2009;75(4):435-439.

11. Bagnis C, Marshansky V, Breton S, Brown D. Remodeling the cellular profile of collecting ducts by chronic carbonic anhydrase inhibition. Am J Physiol Renal Physiol. 2001;280(3):F437-F448.

12. Hafner P, Grimaldi R, Capuano P, Capasso G, Wagner CA. Pendrin in the mouse kidney is primarily regulated by $\mathrm{Cl}^{-}$excretion but also by systemic metabolic acidosis. Am J Physiol Cell Physiol. 2008;295(6):C1658-C1667.

13. Valentin G, Haas P, Gilmour D. The chemokine SDF1a coordinates tissue migration through the spatially restricted activation of Cxcr7 and Cxcr4b. Curr Biol. 2007;17(12):1026-1031.

14. Wenger RH, Stiehl DP, Camenisch G. Integration of oxygen signaling at the consensus HRE. Sci STKE. 2005;2005(306):re12.

15. Sutton A, et al. Stromal cell-derived factor-1/ chemokine (C-X-C motif) ligand 12 stimulates human hepatoma cell growth, migration, and invasion. Mol Cancer Res. 2007;5(1):21-33.

16. Stoos BA, Náray-Fejes-Tóth A, Carretero OA, Ito S, Fejes-Tóth G. Characterization of a mouse cortical collecting duct cell line. Kidney Int. 1991;39(6):1168-1175.

17. Gaeggeler HP, et al. Mineralocorticoid versus glucocorticoid receptor occupancy mediating aldosterone-stimulated sodium transport in a novel renal cell line. J Am Soc Nephrol. 2005;16(4):878-891.

18. Lee K, Zhang H, Qian DZ, Rey S, Liu JO, Semenza GL. Acriflavine inhibits HIF-1 dimerization, tumor growth, and vascularization. Proc Natl Acad Sci U S A. 2009;106(42):17910-17915.

19. Curthoys NP, Moe OW. Proximal tubule function and response to acidosis. Clin J Am Soc Nephrol. 2014;9(9):1627-1638.

20. Duong Van Huyen JP, et al. GDF15 triggers homeostatic proliferation of acid-secreting collecting duct cells. JAm Soc Nephrol. 2008;19(10):1965-1974.

21. Welsh-Bacic D, Nowik M, Kaissling B, Wagner CA. Proliferation ofacid-secretory cells in the kidney during adaptive remodelling of the collecting duct. PLoS One. 2011;6(10):e25240.

22. Tsuruoka S, Schwartz GJ. Metabolic acidosis stimulates $\mathrm{H}+$ secretion in the rabbit outer medullary collecting duct (inner stripe) of the kidney. J Clin Invest. 1997;99(6):1420-1431.

23. Veldkamp CT, Peterson FC, Pelzek AJ, Volkman $\mathrm{BF}$. The monomer-dimer equilibrium of stromal cell-derived factor-1 (CXCL 12) is altered by $\mathrm{pH}$, phosphate, sulfate, and heparin. Protein Sci. 2005;14(4):1071-1081.

24. Al-Awqati Q. Terminal differentiation in epithelia: the role of integrins in hensin polymerization. Annu Rev Physiol. 2011;73:401-412.

25. Weiner ID, Hamm LL. Regulation of intracellular $\mathrm{pH}$ in the rabbit cortical collecting tubule. J Clin Invest. 1990;85(1):274-281.

26. Silver RB, Frindt G, Palmer LG. Regulation of principal cell $\mathrm{pH}$ by $\mathrm{Na} / \mathrm{H}$ exchange in rabbit cortical collecting tubule. J Membr Biol. 
1992;125(1):13-24.

27. Sun X, et al. Deletionof the $\mathrm{pH}$ sensor GPR4 decreases renal acid excretion. J Am Soc Nephrol. 2010;21(10):1745-1755.

28. Mekhail K, Gunaratnam L, Bonicalzi ME, Lee S. HIF activation by $\mathrm{pH}$-dependent nucleolar sequestration of VHL. Nat Cell Biol. 2004;6(7):642-647.

29. Willam C, et al. Inconsistent effects of acidosis on HIF-alpha protein and its target genes. Pflugers Arch. 2006;451(4):534-543.

30. de Brito-Ashurst I, Varagunam M, Raftery MJ, Yaqoob MM. Bicarbonate supplementation slows progression of CKD and improves nutritional status. J Am Soc Nephrol. 2009;20(9):2075-2084.

31. Loniewski I, Wesson DE. Bicarbonate therapy for prevention of chronic kidney disease progression. Kidney Int. 2014;85(3):529-535.

32. Wesson DE, Simoni J, Broglio K, Sheather S. Acid retention accompanies reduced GFR in humans and increases plasma levels of endothelin and aldosterone. Am J Physiol Renal Physiol. 2011;300(4):F830-F837.

33. Hu J, Discher DJ, Bishopric NH, Webster KA.
Hypoxia regulates expression of the endothelin-1 gene through a proximal hypoxia inducible factor- 1 binding site on the antisense strand. Biochem Biophys Res Commun. 1998;245(3):894-899.

34. Knowles J, Loizidou M, Taylor I. Endothelin-1 and angiogenesis in cancer. Curr Vasc Pharmacol. 2005;3(4):309-314.

35. Bleul CC, Fuhlbrigge RC, Casasnovas JM, Aiuti A, Springer TA. A highly efficacious lymphocyte chemoattractant, stromal cell-derived factor 1 (SDF-1). J Exp Med. 1996;184(3):1101-1109.

36. Tögel F, Isaac J, Hu Z, Weiss K, Westenfelder C. Renal SDF-1 signals mobilization and homing of CXCR4-positive cells to the kidney after ischemic injury. Kidney Int. 2005;67(5):1772-1784.

37. Wang A, et al. CXCR4/CXCL12 hyperexpression plays a pivotal role in the pathogenesis of lupus. JImmunol. 2009;182(7):4448-4458.

38. Hostetter TH, Meyer TW, Rennke HG, Brenner BM. Chronic effects of dietaryprotein in the rat with intact and reduced renal mass. Kidney Int. 1986;30(4):509-517.

39. Lotan D, Sheinberg N, Kopolovic J, Dekel B. Expression of SDF-1/CXCR4 in injured human kidneys. Pediatr Nephrol. 2008;23(1):71-77.

40. Cosson MA, et al. Long-term outcome in methylmalonic aciduria: a series of 30 French patients. Mol Genet Metab. 2009;97(3):172-178.

41. Lo YF, et al. Severe metabolic acidosis causes early lethality in NBC1 W516X knock-in mice as a model of human isolated proximal renal tubular acidosis. Kidney Int. 2011;79(7):730-741.

42. Zhao H, et al. Role of fibroblast growth factor receptors 1 and 2 in the ureteric bud. Dev Biol. 2004;276(2):403-415.

43. Miller RL, Zhang P, Chen T, Rohrwasser A, Nelson RD. Automated method for the isolation of collecting ducts. Am J Physiol Renal Physiol. 2006;291(1):F236-F245.

44. Purkerson JM, Heintz EV, Nakamori A, Schwartz GJ. Insights into acidosis-induced regulation of SLC26A4 (pendrin) and SLC4A9 (AE4) transporters using three-dimensional morphometric analysis of $\beta$-intercalated cells. Am J Physiol Renal Physiol. 2014; 307(5):F601-F611.

45. Eladari D, et al. Expression of RhCG, a new putative $\mathrm{NH}(3) / \mathrm{NH}(4)(+)$ transporter, along the rat nephron. J Am Soc Nephrol. 2002;13(8):1999-2008. 